\title{
Indicadores bacteriológicos de contaminación fecal en los ríos de Cuenca, Ecuador
}

\section{Bacteriological indicators of fecal contamination in the rivers of Cuenca, Ecuador}

\author{
Guillermina. PautaCalle. ${ }^{*}$ (D), Gabriela B. Vázquez G. ${ }^{\text {(D) }}$, Andrea F. Abril. T. ${ }^{1}$ iD , Carlos S. Torres I. ${ }^{2}$, Miriam C. \\ Loja-Sari. ${ }^{3}$, Andrea J. Palta-Vera. ${ }^{3}$ \\ ${ }^{1}$ Departamento de Ingeniería Civil, Facultad de Ingeniería, Universidad de Cuenca. Cuenca. Dirección Postal: 01.01.168 \\ 2 Departamento de Agropecuarias, Facultad de Ciencias Agropecuarias, Universidad de Cuenca. Dirección Postal: 01.01.168 \\ ${ }^{3}$ Departamento de Bioquímica y Farmacia, Facultad de Ciencias Químicas, Universidad de Cuenca, Dirección Postal: \\ 01.01 .168 \\ *Autor para correspondencia: guillermina.pauta@ucuenca.edu.ec \\ Fecha de recepción: 7 de julio de 2020 - Fecha de aceptación: 19 de agosto de 2020
}

\begin{abstract}
RESUMEN
Ante la necesidad de un control fiable de la condición microbiológica del agua es imprescindible la selección de indicadores de contaminación fecal sensibles a cambios en la calidad. En esta investigación se revisó la contaminación de los ríos de la ciudad de Cuenca: Tomebamba, Tarqui, Yanuncay y Machángara, empleando indicadores bacterianos tradicionales como los Coliformes Totales y Coliformes Fecales, y además los Estreptococos Fecales y Enterococos por su importancia en estudios de calidad de agua como indicadores alternativos y/o complementarios; todos los organismos proceden del tracto gastrointestinal del hombre y de los animales de sangre caliente y son excretados a través de las heces. Se realizaron tres campañas de monitoreo en cada río cubriendo períodos hidrológicos representativos: caudal alto, medio y bajo y en estaciones específicas, con un total de 78 muestras puntuales; se utilizó la técnica de los Tubos Múltiples expresado como NMP/100 ml, para la cuantificación de los indicadores. Los resultados evidenciaron diferencias significativas de calidad entre tramos de cuenca y mostraron que los Estreptococos Fecales y los Enterococos se desempeñan como indicadores satisfactorios de contaminación fecal; aportan información al momento de definir los usos del recurso y complementan el diagnóstico brindado por los indicadores tradicionales; las relaciones entre indicadores permitieron identificar las posibles fuentes de contaminación. La evaluación integral de la calidad microbiológica de los cuerpos superficiales sugiere el uso de indicadores tradicionales y alternativos, sobre todo en ambientes peculiares, a la vez que permite tomar medidas correctivas específicas para el control de la contaminación.
\end{abstract}

Palabras clave: Ríos, coliformes fecales, estreptococos fecales, enterococos.

\begin{abstract}
Given the necessity to reliably control the microbiological condition of water, it is recommended to select indicators of fecal contamination sensitive to changes in quality. In this research, the contamination of the rivers Tomebamba, Tarqui, Yanuncay, and Machángara of the city of Cuenca was analyzed, using the traditional bacterial indicators Total Coliforms and Fecal Coliforms. In parallel, the bacterial indicators Fecal Streptococci and Enterococci were used as alternative and/or complementary indicators, given their evidence shown in several water quality studies. All these organisms come from the gastrointestinal tract of man and warm-blooded animals and are excreted through the feces. Three monitoring campaigns were conducted in each river during representative hydrological flow conditions, respectively of high, medium, and low flow. A total of 78 samples was collected, and the Multiple Tubes technique, expressed as MPN/100 ml, was used for the quantification of the indicators. The results showed significant differences in quality between the sections of the 4 rivers and suggest that Fecal Streptococci and Enterococci perform satisfactory as indicators of fecal contamination. They provide accurate and reliable information with respect to the safe uses of the water resource and complement the diagnosis obtained by the traditional indicators. The relationships between the indicators permitted to identify possible sources of contamination. Furthermore, the comprehensive evaluation of the microbiological water quality of the examined rivers suggests that the use of traditional and alternative indicators, especially in peculiar environments, permits to define the most appropriate corrective measures to control the contamination.
\end{abstract}

Keywords: Rivers, fecal coliforms, fecal streptococci, enterococci. 
1.

\section{INTRODUCCION}

Usualmente la evaluación de la calidad microbiológica de los ríos se realiza utilizando los indicadores tradicionales del grupo Coliforme: Coliformes totales, Coliformes termotolerantes o fecales, y Escherichia Coli (E. Coli), y son los microorganismos estipulados en la Normativa Ecuatoriana vigente "Texto Unificado de la Legislación Ambiental Secundaria Medio Ambiente" (TULSMA), Libro VI, Anexo 1, a través de los cuales se definen los usos del recurso. El fundamento para su empleo radica en que estas bacterias son excretadas a través de las heces fecales del hombre y de los animales de sangre caliente, por lo tanto su presencia en el agua se asocia a una contaminación fecal y con ella al riesgo de que el agua vehiculice bacterias patógenas; no obstante y aunque no existe un indicador ideal, algunas investigaciones demuestran ciertas limitaciones del grupo coliforme ya que no siempre se ajusta a todas las condiciones naturales, ni permite identificar la fuente de contaminación; en este sentido estudios actuales sugieren el uso de un nuevo grupo, los estreptococos fecales y enterococos como indicadores alternativos $\mathrm{y} / \mathrm{o}$ complementarios que incorporan nuevos criterios al definir la calidad de los cuerpos receptores. La presente investigación se enfoca en la comparación de estos dos grupos de indicadores destacando sus bondades y limitaciones, y en la interpretación en términos de calidad que debe darse a cada uno de ellos, para lo cual se exponen los aspectos relativos más importantes de esta temática y los resultados de investigaciones afines.

E. Coli es abundante en las heces de humanos y animales; la WHO (1997) menciona una concentración de 10E9 células/gramo, y puede ser detectada en aguas naturales sujetas a contaminación fecal reciente (Vanegas, 2012). Las heces fecales se dispersan fácilmente a través de las masas de agua superficiales y las bacterias del tracto intestinal transportadas no suelen sobrevivir en el medio acuático; están sometidas a un estrés fisiológico y gradualmente pierden la capacidad de producir colonias en medios diferenciales y selectivos (Arcos, Ávila, Estupiñán, \& Gómez, 2005). La falta de nutrientes y las condiciones ecológicas severas en ambientes templados evitan que E. coli pueda sostener una división celular de la población fuera del hospedante animal (Larrea-Murrell, Rojas-Badía, Romeu-Álvarez, Rojas-Hernández, \& Heydrich-Pérez, 2013). Su velocidad de mortalidad depende de la temperatura del agua, los efectos de la luz solar, las poblaciones de otras bacterias presentes, y la composición química del agua. Por lo tanto, la presencia de coliformes indica "contaminación bacteriana reciente" y constituye un indicador de degradación de los cuerpos de agua (Arcos et al., 2005).

Sin embargo en varios estudios se ha demostrado que las bacterias coliformes y $E$ Coli no siempre cumplen este cometido; las condiciones ambientales de temperatura, radiación solar, concentración de nutrientes y materia orgánica, permite en entornos de los trópicos su desarrollo y proliferación y son detectados en niveles que no reflejan la extensión original de la contaminación fecal, o aún peor se vuelven autóctonos de estos ecosistemas acuáticos pudiendo ser aislados en ausencia de una fuente fecal conocida (Méndez, 2004; RIPDA CYTED, 2016; Campos, 1983), y no siempre su ocurrencia tiene una implicación en la salud pública (Macler \& Merkle, 2000). Evaluaciones de cuerpos de agua en países como Nigeria,
Hawái, Nueva Guinea, Puerto Rico, Sierra Leona y Costa de Marfil, reportan elevados niveles de E. Coli en ausencia de una fuente fecal identificada; en contraste, otros estudios en países tropicales también como Uganda, la catalogan como un indicador satisfactorio de contaminación fecal (Larrea-Murrell et al., 2013).

E Coli experimenta modificaciones fisiológicas que le permite adaptarse sólo parcialmente a condiciones de estrés en agua salina, y alteran el funcionamiento de ciertas enzimas como b-galactosidasa responsable de la producción de gas y fermentación de lactosa, respuestas que se utilizan para su identificación en el cultivo (Barrera et al., 1998); esta puede ser la razón de que en monitoreos de cuerpos de agua contaminados, algunas muestras reportan ausencia de $E$. Coli con predominio de estreptococos fecales, atribuibles a materia fecal de aves circundantes en la zona (Namhira, Barrera, \& Márquez, 2002). Se demuestra que aguas de cisternas contaminadas con algunos géneros de Pseudomonas inhiben el desarrollo de E. Coli mediante la producción de una substancia "pseudocin"; por lo tanto, el agua podría satisfacer falsamente el requisito de "ausencia de coliformes" (Marchand, 2002).

Los coliformes fecales y fundamentalmente E. Coli tradicionalmente han sido empleados como indicadores de contaminación fecal; pero hay evidencia de la poca relación que existe entre su presencia y la de los patógenos (Botero, Zambrano, Oliveros, \& León, 2002); por sí solos no revelan el origen de la contaminación (animal o humana) (Kacar, 2011); son de gran utilidad para aguas de bebida, pero no tienen la misma importancia en sistemas naturales debido a la probable presencia de coliformes autóctonos en ciertas condiciones.

Finalmente se reconoce a $E$. Coli como un indicador válido para detectar contaminación reciente y dada su aplicación histórica resulta de valor para estudiar fluctuaciones entre largos períodos, sobre todo cuando no se dispone de registros del pasado de otros indicadores (Cambruzzi, 2016). Dependiendo del objetivo del estudio es útil para identificar problemas ambientales de salud pública, y en investigaciones específicas demuestra una correlación positiva entre la densidad poblacional y su contenido en los cuerpos receptores (Calvo \& Mora, 2012). A pesar de las restricciones E Coli sigue siendo el bioindicador obligatorio en los sistemas de abastecimiento de varios países. Este género incluye cepas patógenas y no patógenas y corresponde al $80 \%$ de la microflora intestinal normal, donde generalmente es inofensiva (Ríos, Agudelo, \& Gutiérrez, 2017).

Investigaciones recientes proponen el uso de los estreptococos y del género enterococos como indicadores de contaminación fecal, cuya aplicación debe analizarse para cada caso en particular; los argumentos que sustentan su uso se exponen a continuación. Los estreptococos ofrecen la posibilidad de identificar el origen de la contaminación fecal: humana o animal, puesto que hay especies específicas; este tema es de mucha importancia en los últimos años sobre todo cuando hay presencia de animales de producción: vaca, cerdo, oveja, caballo, gallina y pato; en todos ellos se encuentran coliformes y estreptococos siendo estos últimos más abundantes. (Arcos et al., 2005).

Los estreptococos fecales comprenden microorganismos del género enterococos y algunas especies de estreptococos como: estreptococos bovis y estreptococos 
equinus; estas especies son más abundantes en heces de animales (RIPDA CYTED, 2016; Calderon, 2014) y son utilizadas como indicadoras de contaminación producida por animales de granja; mueren rápidamente en el medio exterior, por lo que su detección indica contaminación reciente de origen animal (Larrea-Murrell et al., 2013; Díaz, Rodriguez, \& Raisa, 2010); todos pertenecen al grupo D de Lancefield (Méndez, 2004). Los enterococos son un subgrupo de los estreptococos fecales que crecen en caldos de cultivo conteniendo $6.5 \%$ de cloruro de sodio, a pH 9.6; hidrolizan la esculina en presencia de $40 \%$ de bilis o 4\% de sales biliares (Méndez, 2004) y sobreviven después del calentamiento a $60^{\circ} \mathrm{C}$ durante 30 min (Díaz et $a l$., 2010). Poseen una gruesa pared bacteriana y forma esférica tipo coco, que le confiere gran resistencia a fuerzas físicas y a variaciones de la presión osmótica del medio externo, y por tanto mayor persistencia en ambientes acuáticos, al compararlos con los coliformes en general (Cambruzzi, 2016). Enterococos faecalis es considerado específicamente de fuentes humanas, mientras que enterococos faecium y otras especies indican contaminación de otras fuentes (Larrea-Murrell et al., 2013; Díaz et al., 2010).

Otra clasificación establece que las especies de enterococos fecales que se encuentran en aguas contaminadas pueden ser divididas en dos grupos. En el primero se encuentran enterococcus faecalis, enterococcus faecium y enterococcus durans, normalmente presentes en las heces de humanos y animales; el segundo grupo incluye estreptococos bovis, estreptococos equinus y enterococcus avium, los cuales no se encuentran comúnmente en las heces humanas. La identificación de la especie puede ser un mejor indicativo de la fuente de contaminación (Arcos et al., 2005; Calderon, 2014; Lombardo, 2018). La investigación de virus específicos relacionados con las especies contribuye en este objetivo, como se observa en los estudios realizados por Bonifaz (2018) y Fout, Borchardt, Kieke, \& Karim (2017). Se puede concluir entonces que los enterococos son un tipo de estreptococos con características más específicas y abarca especies que pueden presentarse tanto en humanos como en animales.

La concentración de enterococos intestinales en las heces humanas es generalmente de un orden de magnitud menor que E. Coli. (EcuRed, 2001); son más persistentes en el agua y en suelos contaminados (Barrera, Chang, Figueroa, Guzmán, Hérnandez, \& Saavedra, 1998); en su mayoría no son habitantes ambientales normales y pueden ser utilizados para conocer el origen de la contaminación (Cambruzzi, 2016); son importantes en situaciones donde se sabe que hay contaminación fecal pero no se detectan coliformes como ocurre cuando las descargas son intermitentes o más antiguas, de modo que mueren los coliformes fecales y E. Coli, pero permanecen los estreptococos (RIPDA CYTED, 2016; Marchand, 2002; Arcos et al., 2005; Cohen \& Shuval, 1972). Se estima que la supervivencia de E. Coli en aguas marinas, aproximadamente es de 0.8 días, y de los enterococos de 2.4 días (Larrea-Murrell et al., 2013). Por su estabilidad en medios salinos, se recomienda como indicadores para vigilar la calidad del agua en playas de uso recreativo, ya que están relacionados directamente con gastroenteritis, enfermedades respiratorias, conjuntivitis y dermatitis, entre otras (Chagas et al., 2006; Rodríguez, 2011; Arcos et al., 2005; Salas, 2000; Díaz et al., 2010; Lombardo, 2018; Botero et al., 2002).
Los estreptococos simulan mejor las características de sobrevivencia de rotavirus, el cual es uno de los agentes etiológicos de gastroenteritis de mayor prevalencia. Otros estudios evidencian que hay mayor relación entre estreptococos fecales y salmonella que entre coliformes fecales y salmonella; se ha demostrado también una relación positiva entre la frecuencia de trastornos digestivos asociados con la natación y la concentración media de enterococos en agua de mar (Vergaray, Méndez, Morante, Heredia, \& Béjar, 2007; Calderon, 2014). Por su capacidad de respuesta frente a diferentes situaciones de contaminación fecal, la USEPA ha recomendado el uso de los enterococos como indicador de calidad en aguas recreativas por contacto primario o baño (Sinton, Donnison, \& Hastie, 1993). Sin embargo, estudios en la Bahía de la Habana Cuba, señalan que éstos pueden inactivarse por acción de la luz solar y en presencia de sustancias húmicas; se plantea también que estas bacterias pueden incorporarse a las corrientes procedentes de los suelos, por lo que no necesariamente reflejan el grado de contaminación de dichas aguas, ni garantizan el origen fecal (EcuRed, 2001; Lombardo, 2018). Adicionalmente estreptococos faecalis y estreptococos faecium considerados de origen humano, presentan el inconveniente de que han sido aislados de aguas contaminadas con residuos fecales de animales inferiores, detectándose además biotipos de estreptococos faecalis asociados a vegetales e insectos (Campos, 1983).

La Organización Mundial de la Salud (OMS) cataloga a los estreptococos fecales en el examen de la calidad del agua potable, como "indicadores adicionales" de la eficiencia del tratamiento, y para los controles corrientes después del tendido de nuevas cañerías maestras (EcuRed, 2001; Suarez, 2002). Finalmente, este mismo organismo discute la ineficacia de coliformes fecales como indicador de polución fecal y debate los méritos de indicadores alternativos, como enterococos y clostridios sulfito reductores (Díaz et al., 2010); la OMS propuso guías para calidad de aguas recreacionales utilizando estreptococos fecales como organismo indicador (Salas, 2000); la EPA ha dado igual recomendación (EPA, 2012).

Por lo visto, todos los indicadores tienen sus limitaciones al momento de interpretar la calidad del agua; se reconoce entonces que la salud pública no estaría protegida solamente con el empleo del indicador de norma (E. Coli), siendo necesario la inclusión de otros complementarios. Se ha sugerido la diferencia significativa entre la cantidad de coliformes y enterococos descargada por los humanos y animales (Larrea-Murrell et al., 2013); también se conoce que el número de estreptococos fecales en animales de sangre caliente es mucho mayor que el de coliformes y que esta relación es inversa en el hombre (Campos, 1983). Estas relaciones numéricas entre indicadores se usan para identificar la posible fuente de contaminación; aunque hay objeciones debido a las diferencias de los rangos de muerte en el ambiente, a la supervivencia variable de especies de estreptococos fecales y a los métodos para su determinación. (Suarez, 2002; Lombardo, 2018; Botero et al., 2002). Sin embargo, se ha utilizado esencialmente la relación coliforme fecales/estreptococos fecales para diferenciar la contaminación en zonas tropicales, pero su aplicación en zonas templadas como el presente estudio, aún se desconoce (Rivera, de Los Ríos, \& Contreras, 2010).

En vista de la tendencia actual en el uso de nuevos indicadores, el presente estudio tiene por objeto evaluar la 
calidad de los ríos de la ciudad a través de los indicadores tradicionales (coliformes totales y fecales) y para fines de comparación y análisis incluir los indicadores alternativos (estreptococos y enterococos fecales), puesto que la calidad de agua experimenta una variación espacial y temporal, es importante analizar el comportamiento de todos los indicadores en diferentes períodos hidrológicos: estiaje, invierno, y en condiciones intermedias de caudal. En este caso, los resultados también permitirán identificar de forma aproximada el origen de la contaminación, aspecto significativo para introducir las necesarias medidas correctivas. Finalmente debido a los múltiples usos del recurso es preciso verificar el cumplimiento del valor de normativa para coliformes fecales.

\section{MATERIALES Y METODOS}

El programa de monitoreo se llevó a cabo en estaciones establecidas para los cuatro cuerpos superficiales de la ciudad, los ríos Tomebamba, Yanuncay, Machángara y Tarqui (Fig. 1).

Se realizaron tres campañas de monitoreo para cada río; la primera del 04 al 25 de febrero del 2019 que corresponde a la época de lluvia, la segunda del 24 de junio al 03 de julio en caudal medio; y la tercera campaña del 11 al 23 de septiembre en época de verano; es decir doce campañas de muestreo con un total de setenta y ocho muestras. Se establecieron para los ríos Tomebamba, Tarqui, y Yanuncay, siete estaciones de muestreo, y cinco para el

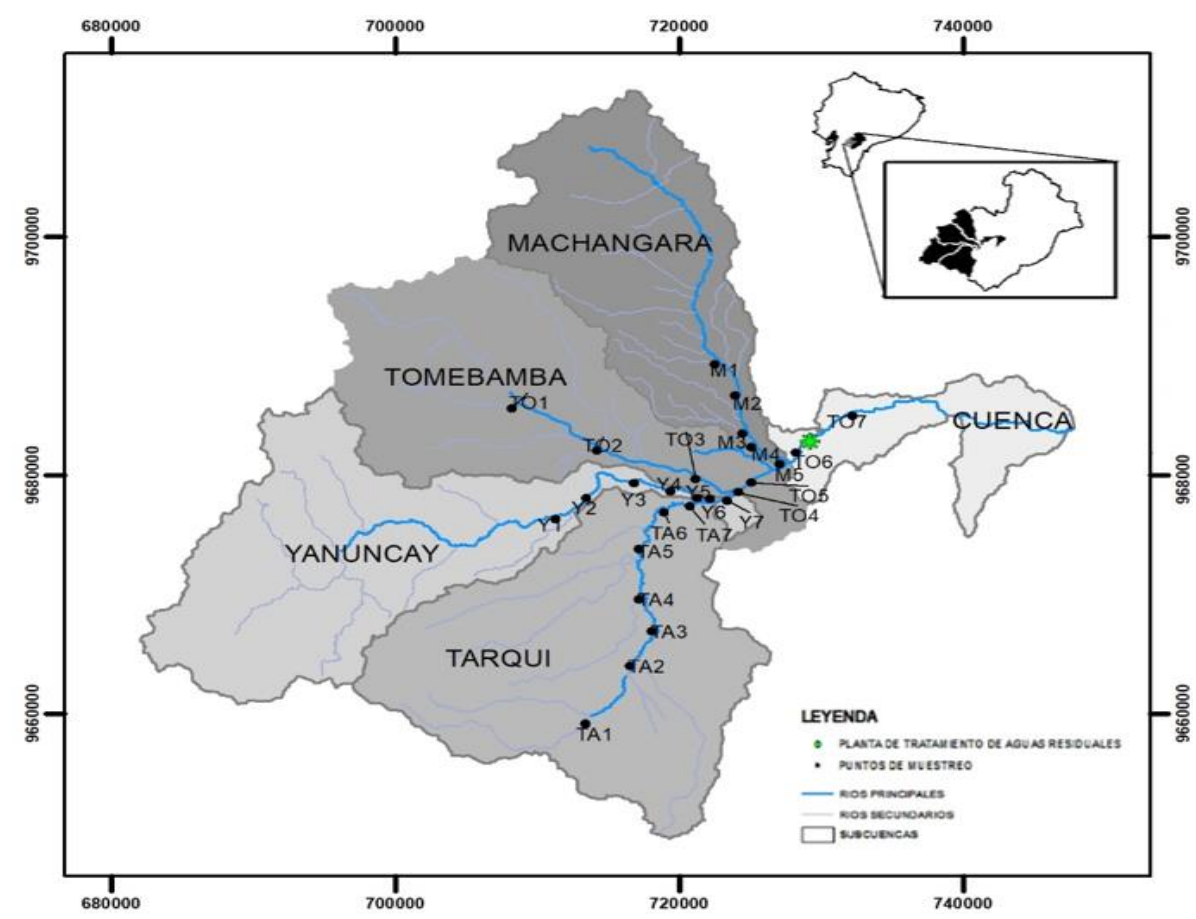

Figura 1. Área de estudio y estaciones de monitoreo en las cuatro subcuencas evaluadas.

Tabla 1. Referencia de los sitios de monitoreo en los cuatro ríos estudio.

\begin{tabular}{|c|c|c|c|c|c|}
\hline Subcuenca & Código & Referencia & Subcuenca & Código & Referencia \\
\hline \multirow{7}{*}{ Río Tarqui } & TA1 & Portete & \multirow{7}{*}{$\begin{array}{c}\text { Río } \\
\text { Tomebamba }\end{array}$} & TO1 & Llaviuco \\
\hline & TA2 & $\begin{array}{l}\text { Después de la junta con el } \\
\text { río Cumbe }\end{array}$ & & TO2 & Sayausí \\
\hline & TA3 & Tarqui & & TO3 & \multirow{4}{*}{$\begin{array}{l}\text { Puente del Vado } \\
\text { Empresa Eléctrica } \\
\text { Antes de la Junta con la } \\
\text { Quebrada Milchichig } \\
\text { Antes de la descarga de la } \\
\text { PTAR* de Cuenca }\end{array}$} \\
\hline & TA4 & Zona Franca & & TO4 & \\
\hline & TA5 & $\begin{array}{l}\text { Después de la junta con el } \\
\text { río Zhucay }\end{array}$ & & TO5 & \\
\hline & TA6 & Parque Inclusivo & & TO6 & \\
\hline & TA7 & $\begin{array}{l}\text { Antes de la junta con el río } \\
\text { Yanuncay }\end{array}$ & & TO7 & Challuabamba \\
\hline \multirow{7}{*}{$\begin{array}{c}\text { Río } \\
\text { Yanuncay }\end{array}$} & Y1 & Dispensario Barabón & \multirow{7}{*}{$\begin{array}{c}\text { Río } \\
\text { Machángara }\end{array}$} & & \multirow{7}{*}{$\begin{array}{l}\text { Chiquintad } \\
\text { Ochoa León } \\
\text { Feria de Ganado } \\
\text { Parque Industrial } \\
\text { Antes de la Junta con el río } \\
\text { Tomebamba }\end{array}$} \\
\hline & $\mathrm{Y} 2$ & Inmaculada de Barabón & & M1 & \\
\hline & Y3 & San Joaquín & & M2 & \\
\hline & Y4 & Avenida Loja & & M3 & \\
\hline & Y5 & Tres Puentes & & M4 & \\
\hline & Y6 & Redondel de la UDA & & \multirow[t]{2}{*}{ M5 } & \\
\hline & Y7 & Parque el Paraíso & & & \\
\hline
\end{tabular}

*PTAR: Planta de Tratamiento de Agua Residual. UDA: Universidad del Azuay 
río Machángara. Las estaciones TO6 y TO7 ya están ubicadas en el río Cuenca, arteria hidrográfica que se conforma a partir de la unión del río Tomebamba con el Machángara (Tabla 1). Las muestras fueron puntuales, captadas en sentido contrario a la corriente y procurando la representatividad del cuerpo de agua que se quiere caracterizar; se recolectaron en frascos de vidrio estériles de $500 \mathrm{ml}$ de capacidad con tapa esmerilada, debidamente etiquetados y dejando una cámara de aire para homogenizar la solución antes de procesarla. Las muestras se transportaron en un enfriador con geles refrigerantes a $4^{\circ} \mathrm{C}$ para garantizar su estabilidad y fueron procesadas en el Laboratorio de Sanitaria de la Facultad de Ingeniería de la Universidad de Cuenca. Los métodos utilizados se describen y están disponibles en "Estándar Métodos para el Análisis de las Aguas y Aguas Residuales, ed. 21, las Secciones 10200B, 9221B, 9221C, y 9230B).

\section{Determinación de Coliformes Totales}

Fase Presuntiva: Se usó caldo lauril triptosa con púrpura de bromocresol el cual permite la recuperación de los microorganismos dañados presentes en la muestra y favorece el aprovechamiento de la lactosa como fuente de carbono; se incubaron las muestras diluidas a $35.5^{\circ} \mathrm{C} \pm 0.5^{\circ} \mathrm{C}$ durante $24 \pm 2$ horas considerándose como positivos los tubos con producción de gas, turbidez y un ambiente ácido (color amarillo). Los tubos que no presentan estas características se reincuban para volverlo a examinar al final de $48 \pm 3$ horas.

Fase confirmatoria: De los tubos considerados positivos, con un asa estéril de $3 \mathrm{~mm}$ de diámetro, se transfiere el cultivo a tubos de fermentación que contienen lactosa bilis verde brillante; se incuban los tubos a $35.5^{\circ} \mathrm{C} \pm 0.5^{\circ} \mathrm{C}$ durante $48 \pm 3$ horas; la formación de gas en el vial invertido en el medio de fermentación representó un resultado positivo en la fase confirmatoria, calculándose el valor del NMP a partir del número de tubos positivos.

\section{Determinación de Coliformes Fecales}

De los tubos positivos del caldo lauril triptosa con púrpura de bromocresol, se transfirió una muestra con un asa estéril de $3 \mathrm{~mm}$ de diámetro al medio EC y se incubo a $44.5^{\circ} \mathrm{C} \pm 0.2$ durante $24 \pm 2$ horas. Se consideró como reacción positiva la presencia de gas y turbidez. Los resultados se expresaron en NMP/100 ml de muestra. Estos organismos se denominan también coliformes termotolerantes.

\section{Determinación de Estreptococos Fecales}

Prueba presuntiva: Se inoculó la muestra en tubos con caldo azida glucosa y se incubaron a $35.5^{\circ} \mathrm{C} \pm 0.5^{\circ} \mathrm{C}$ durante $24-48$ horas. Se consideraron positivos aquellos tubos que presentaron turbidez y sedimento. Prueba confirmatoria: De cada tubo positivo en la prueba presuntiva, se pasa una muestra para siembra por estrías en placas con agar Pfizer para enterococos, incubando la placa invertida a $35.5^{\circ} \mathrm{C}$ durante $24-48$ horas. La formación de colonias pardo-negruzcas con halos marrones confirmó la presencia de estreptococos fecales.

\section{Determinación de Enterococos Fecales}

Una muestra de cada colonia positiva para estreptococos fecales fue transferida a tubos con caldo de infusión encéfalo corazón (BHI) que contiene $\mathrm{NaCl}$ al $6.5 \%$ incubándose a $44.5^{\circ} \mathrm{C}$ durante 3 horas; los tubos con turbidez se consideraron positivos para enterococos. Finalmente se calculó el NMP/100 ml, para estreptococos fecales y enterococos. Según esta técnica entonces, los enterococos son un subgrupo de los estreptococos que poseen características específicas.

\section{Relación Coliformes Fecales/Estreptococos Fecales}

La relación coliforme fecales/estreptococos fecales, tiene por objeto estimar la fuente de contaminación; cuando esta relación es mayor a 4 , se presume que la contaminación es debida a desechos humanos; valores menores a 0.7 indican una contaminación por desechos animales y el intervalo entre 0.7 y 4 supone un patrón de contaminación mixta. (Larrea-Murrell et al., 2013; Marchand, 2002; Gamarra, Barrena, Baboza, Rascón, \& Corroto, 2018). El fundamento de esta relación se basa en que los estreptococos fecales son excretados en mayor cantidad por las heces fecales de animales (Glynn Henry \& Gary Heinke, 2009).

\section{Análisis estadístico}

Se utilizó el programa de Microsoft Excel 2017, donde se compilaron todos los datos de los ensayos, y para la representación se usaron gráficas en columnas. Los datos fueron analizados en el software SPSS (Statistical Product and Service Solutions). Para conocer la relación entre variables se usó la prueba no paramétrica de KruskalWallis con un nivel de significancia de $\mathrm{p}<0.05$ para el análisis; y la variabilidad de los indicadores para cada río, se representa a través de los diagramas de cajas.

\section{RESULTADOS Y DISCUSION}

En la Figura 2 se compara la magnitud de los coliformes fecales como representativo de los indicadores tradicionales, con su "equivalente" los estreptococos fecales como representativo de los alternativos, para cada río y en los tres caudales; en cada gráfica se visualiza con línea entrecortada el valor de referencia establecido por la normativa TULSMA, fijado en $1000 \mathrm{NMP} / 100 \mathrm{ml}$ para coliformes fecales. En los ríos Tomebamba y Yanuncay en los primeros sitios de monitoreo y en los tres períodos hidrológicos el indicador se encuentra dentro del valor de referencia, esto debido a que se trata de zonas poco intervenidas, con menor influencia de la urbanización y la calidad es independiente del caudal; en las zonas medias y bajas se va incrementando progresivamente la contaminación y los niveles detectados ya no son compatibles para la mayor parte de los usos del agua. En el río Tarqui en cambio, el incumplimiento del valor de normativa y por lo tanto la limitación de los usos se produce en todas las estaciones y así mismo es independiente del caudal; y en el río Machángara sólo en la estación Chiquintad, se satisface el requisito. Por lo tanto, en su trayecto por el área urbana todos los ríos experimentan un deterioro significativo de su calidad microbiológica.

En todos los ríos y en la casi totalidad de los sitios de monitoreo, la magnitud de los coliformes fecales es mayor que los estreptococos fecales, lo que significa que la materia fecal contaminante en los ríos descarga mayor cantidad de coliformes, y el incremento progresivo de 

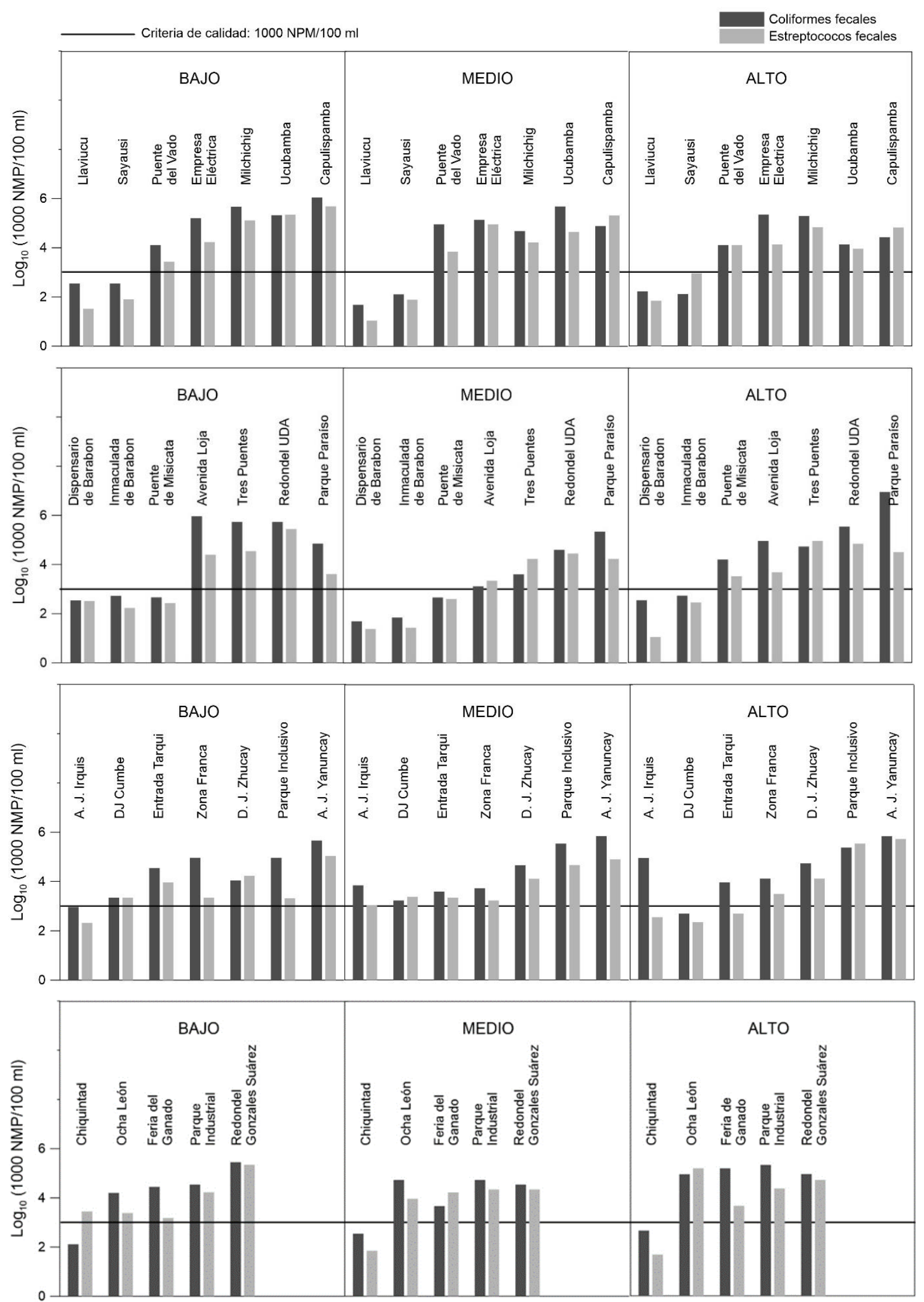

Figura 2. Comparación de coliformes fecales y estreptococos fecales para los Ríos Tomebamba, Yanuncay, Tarqui y Machángara (de arriba abajo). 


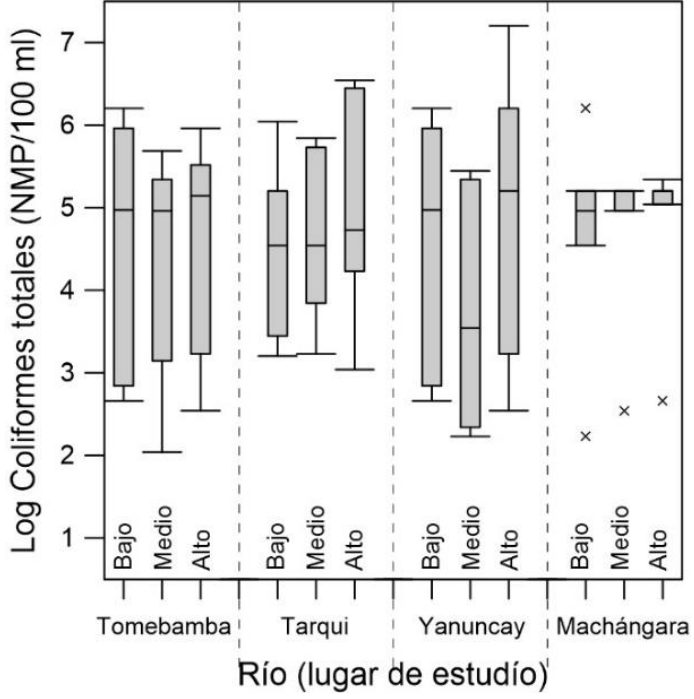

(a)

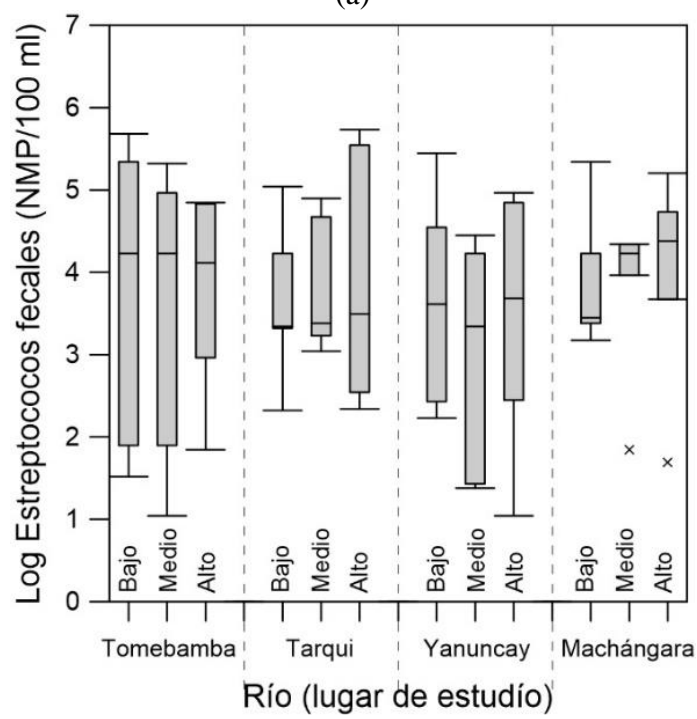

(c)

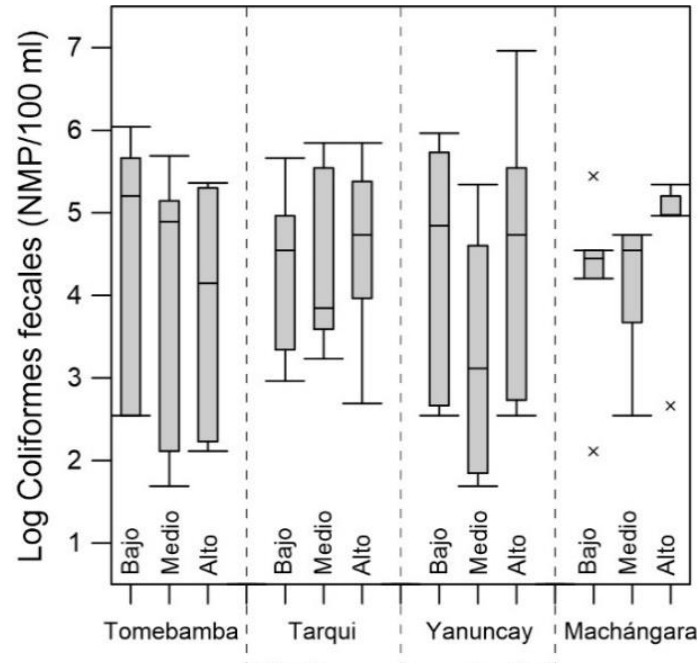

Río (lugar de estudío)'

(b)

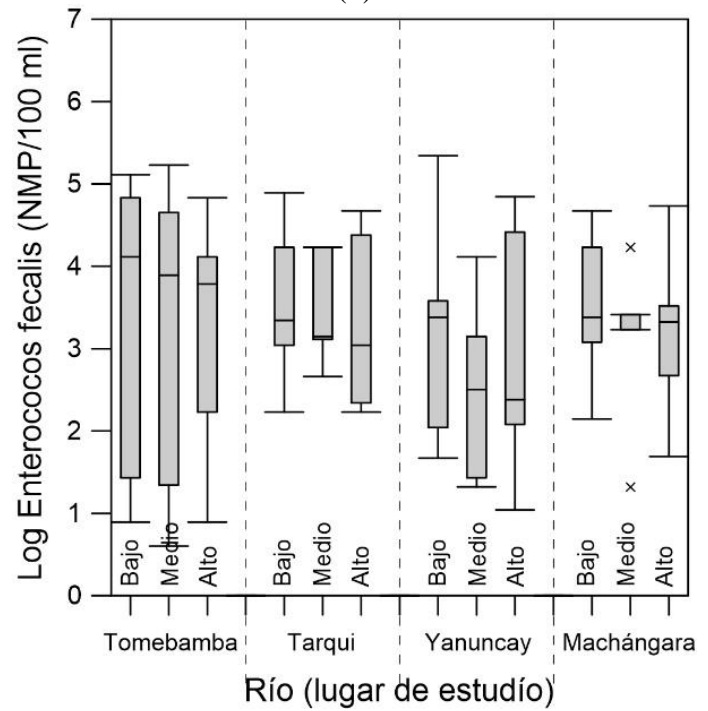

(d)

Figura 3. Coliformes totales (a), Coliformes fecales (b), Estreptococos fecales (c) y Enterococos (d) en todos los ríos, en los tres períodos hidrológicos.

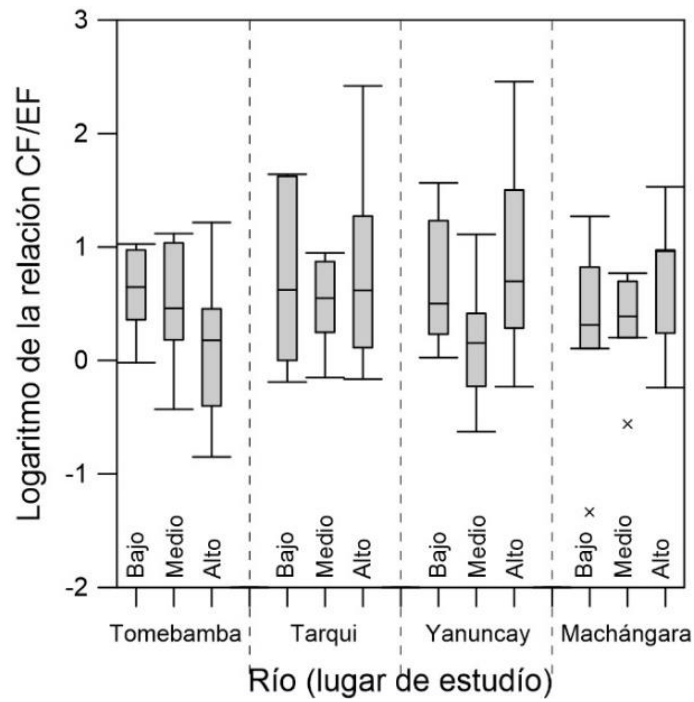

Figura 4. Logaritmo de la relación coliformes fecales / estreptococos fecales en todos los ríos, en los tres períodos. 
ambos indicadores que siguen la misma tendencia a medida que avanza su recorrido, indica que la contaminación se intensifica lo que tiene relación con los usos del suelo instaurados en las subcuencas de estudio, predominantemente la urbanización. Sin embargo, para evaluar este incremento, mejores indicadores representarían los estreptococos por su mayor estabilidad tanto en el medio acuático (hábitat secundario) cuanto en la solución "muestra" captada para el análisis; sus características físicas y fisiológicas les permiten mayor estabilidad en las cifras, y por tanto más representatividad de la contaminación original.

La densidad original de los coliformes puede modificarse dentro de la masa de agua en estaciones específicas; por ejemplo, en los tramos altos de los ríos las condiciones de temperatura, la escasez de nutrientes y otros factores ambientales propios de los climas templados, pueden generar ambientes de estrés e inhibir su desarrollo, por lo que la magnitud detectada puede ser menor, no reflejando la contaminación real de la zona y tampoco la relación entre indicadores y patógenos. En las últimas estaciones de monitoreo en cambio, debido al permanente ingreso de agua residual doméstica que constituye un aporte constante de materia orgánica, nutrientes de fósforo y nitrógeno, (se conoce que las heces humanas contienen entre 5 y $7 \%$ de nitrógeno, y entre 3 y $5.4 \%$ de fósforo, en base seca) (Formica, Sacchi, \& Campodonico, 2015) y al incremento de temperatura, se generan condiciones propicias que favorecen su reproducción mostrando una población microbiana mayor a la original.

La Figuras 3 y 4 muestra la variabilidad de los datos a través de diagramas de cajas para cada indicador y para la relación coliformes/estreptococos en todos los ríos y para cada caudal o período hidrológico.

La mayor variabilidad para coliformes totales y fecales se presenta en el río Yanuncay, en cambio para los estreptococos fecales y enterococos en el río Tomebamba; lo que indica la influencia de las condiciones propias y los usos del suelo de cada subcuenca en el comportamiento de los indicadores. También se observa que los valores más bajos para todos los indicadores se presentan en el río Yanuncay y en condiciones de caudal medio, denotando una tendencia de la relación entre el caudal y la calidad microbiológica en esta subcuenca. Para todos los indicadores la menor variabilidad se presenta en el río Machángara, lo que indica que la calidad es más estable y depende menos del período hidrológico; esto debido al efecto de regulación del caudal de la corriente a través de los embalses para el aprovechamiento energético que realiza la Empresa ELECAUSTRO. Sin embargo, de acuerdo a que lo mostrado con los diagramas de cajas y a su vez con las pruebas de significancia de Kruskal-Wallis, en donde se relaciona la magnitud de los indicadores con respecto al caudal o período hidrológico, no se ha encontrado evidencias de que los niveles difieran estadísticamente al menos al 5\% de significancia, pudiendo establecerse únicamente como tendencias encontradas, es decir no hay relación entre la magnitud de los indicadores y el período hidrológico. Al analizar los resultados de los indicadores tradicionales se observa que la magnitud de los coliformes fecales siempre será menor o a lo mucho igual a los coliformes totales, puesto que también existen coliformes de origen no fecal, en el suelo, en el agua y en ambientes característicos; y los coliformes fecales pueden provenir indistintamente del hombre y de los animales. Sin embargo, los dos indicadores presentan la misma tendencia, es decir se incrementan cuando aumenta la contaminación, no existiendo una relación definida entre sus cuantías. Los resultados de los indicadores alternativos nos permiten el siguiente análisis. Por la técnica utilizada en este estudio, los enterococos al representar un subgrupo de los estreptococos también sus números serán menores o a lo mucho igual que éstos; pero los dos son de origen fecal, humano y/o animal, sin que tampoco sea posible establecer una relación definida entre sus magnitudes, aunque sigan la misma tendencia con el curso de los ríos. Los estreptococos que no son enterococos pueden corresponder a especies características como estreptococos bovis y estreptococos equinos y otros, al parecer de origen animal; en tanto que el subgrupo de enterococos en la mayoría de los estudios se reporta corresponden a enterococos faecalis, enterococos faecium, enterococos durans, al parecer más abundantes en las heces de origen humano. Por lo que para un mayor aporte en la identificación de la fuente de contaminación se requieren las pruebas bioquímicas como se indicó en la revisión bibliográfica.

En cuanto a la relación coliformes fecales/estreptococos fecales (CF/EF) (Fig. 4) para predecir en forma aproximada el origen de la contaminación, y aceptando como válida la propuesta de referencia (Glynn Henry \& Gary Heinke, 2009) se observa que en el río Tomebamba predomina la contaminación mixta, lo cual es compatible con la actividad que se desarrolla en la subcuenca. Se observa también que la contaminación de origen humano guarda relación con el período hidrológico. Así la relación coliformes totales/estreptococos fecales, $\mathrm{CT} / \mathrm{EF}>4$, se presenta en cuatro estaciones en estiaje, en tres estaciones en caudal medio y solamente en una en período invernal, esto significa que las descargas de aguas residuales domésticas son diluidas por la escorrentía, y la situación de contaminación es crítica en estiaje. Dos estaciones presentan una relación menor a 0.7: Sayausí sólo en caudal alto, y Challuabamba en caudal alto y medio, denotando que al aumentar el caudal se produce arrastre de la materia fecal de origen animal en ambas estaciones. Llama la atención, el origen antrópico de la contaminación en Llaviuco $(\mathrm{CF} / \mathrm{EF}=10.6)$ y en estiaje, advirtiendo que la condición más crítica de la polución se presenta en verano, lo que sugiere una vigilancia de la zona, restringiendo el tránsito de las personas y/o controlando descargas domiciliarias no identificadas. La estación Empresa Eléctrica, en invierno y en estiaje presenta una relación CT/EF de 16.4 y 9.4 respectivamente, por lo que descargas residuales domésticas son evacuadas permanentemente en esta zona, situación que se agrava por el desborde de los interceptores en invierno.

En conclusión en el río Tomebamba, pese a disponer de interceptores marginales en sus dos orillas, es fuerte el predominio de agua residual doméstica; en el río Yanuncay en cambio, en invierno se produce contaminación difusa por arrastre de materia fecal de origen humano no procedente de alcantarillados no conectados a los sistemas de interceptores marginales, y por eso la mayor parte de las estaciones en invierno presentan una relación $\mathrm{CT} / \mathrm{EF}>4$; la escorrentía debido a la pendiente de la subcuenca hace un "lavado del suelo" arrastrando sólidos suspendidos que incrementa considerablemente la turbiedad y el contenido de bacterias también. La estación Tres Puentes arrastra materia fecal de origen animal en caudal medio y bajo $(\mathrm{CF} / \mathrm{EF}<0.7)$, y finalmente la estación Parque el Paraíso en todos los 
períodos hidrológicos supera la relación de referencia, pero particularmente en invierno con un valor $\mathrm{CF} / \mathrm{EF}=287.5$ denotando contaminación fecal humana y difícil de controlar, más el arribo de aguas residuales domésticas producida por el rebose de los interceptores; y aunque esta condición se produce en forma temporal mientras dure la precipitación, ejerce un impacto negativo considerable en el ecosistema. En esta estación se capta el agua para la laguna recreativa que funciona en el interior del parque, y en la cual se supera en mucho el objetivo de calidad propuesto para este uso. El río Tarqui presenta el mayor número de estaciones en donde la relación $\mathrm{CF} / \mathrm{EF}>4$. De particular interés en A. J. Irquis, con un valor mayor a 4 en todas las condiciones hidrológicas, sobre todo en invierno cuya magnitud asciende a 262.9; esto significa un ingreso permanente de aguas residuales domésticas en esta estación. La actividad ganadera es importante en esta subcuenca, no obstante, sólo en tres estaciones se observa predominio de materia fecal de origen animal y no vinculada al caudal; quizá esto se deba a la poca pendiente del río limitando el escurrimiento superficial hacia los cuerpos receptores. En el río Machángara, también hay un fuerte componente de aguas residuales domésticas, acompañado en menor magnitud de contaminación mixta; las estaciones Ocha León, Feria del Ganado y Chiquintad presentan un predominio de materia fecal de origen animal, pero no hay una tendencia vinculada al caudal.

Estudio similar en ríos de alta montaña constituye el realizado en los ríos Manuaré y Casacará (Colombia); en ambos la magnitud de los coliformes es mayor al de los estreptococos, y la mayor contaminación se presenta en condiciones de estiaje, menos crítica para el río Casacará que mantiene un caudal relativamente estable conservando su capacidad de autodepuración en seca. En este estudio la determinación de los estreptococos fecales permitió establecer el origen agroindustrial como una fuente de contaminación (Barahona, Luna, \& Romero, 2017). Otras estudios llegaron a las siguientes hallazgos: en el río Almendaris (Cuba) en período invernal se incrementa la magnitud de ambos indicadores en algunas estaciones evidenciando el efecto de la contaminación difusa (Chiroles, González, Torres, Valdés, \& Domínguez, 2007); en el estudio del río Sokoto Nigeria, identificó claramente contaminación de origen animal (Rají, Ibrahim, Tytler, \& Ehinmidu, 2015); en la cuenca del Arroyo del Tala (Argentina) al relacionar la carga contaminante del agua con respecto a la capacidad de carga animal media en una subcuenca, predominan los coliformes fecales sobre los estreptococos fecales y enterococos, en más de un orden de magnitud (Chagas $e t$ al., 2007); y en más de dos órdenes de magnitud se revela en el río Sagre en Lérida (España), en donde la relación entre indicadores identifica la contaminación humana preponderante (Rodríguez \& Ramón, 1990). Otros estudios con resultados similares constituyen los efectuados en el río Mfoundi (Camerún) (Djuikom, Njine, Nola, Sikati, \& Jugnia, 2006), y en el río Buyuk Menderes (Turquía) (Kacar, 2011). Mayor densidad de estreptococos con respecto a los coliformes se presentan en el río del Beehar (India) y en ambos períodos hidrológicos, invierno y verano (Singh, Mishra, Lal Dwivedi, \& Kumar, 2019).

En algunos lagos en cambio el nivel de estreptococos es mayor al de los coliformes, demostrando mayor resistencia de aquellos y por lo tanto su mayor significado de contaminación fecal por eventos anteriores, aunque no se identifique la fuente de contaminación (Namhira et al., 2002; Rossen et al., 2008). La evaluación de la calidad en un lago realizado por Barrera et al. (1999), demostró que el alto índice de estreptococos en la parte norte de la laguna se atribuye a los potreros y ranchos con animales de granja, origen que no habría sido identificado sólo con el grupo coliforme. El predominio de los estreptococos en lagos quizá se deba a las diferencias de flujo existentes entre éstos y los ríos; los lagos pueden representar condiciones difíciles para el desarrollo de los coliformes, como niveles de oxígeno disuelto, formación de termoclinas, etc., no así para los estreptococos.

Para diferenciar el origen de la contaminación fecal, algunas investigaciones se basan directamente en la identificación de las especies de enterococos como lo manifiesta Chagas et al. (2006) en sus estudios, demostrando la ausencia de estreptococos faecalis, al parecer de auténtico origen humano y concluyendo que la contaminación era de procedencia animal; aunque no se pueda garantizar si procedente exclusivamente de la actividad ganadera, ya que hay especies asociadas a las aves y otros animales, tanto domésticos como silvestres.

Por lo visto de la comparación de este estudio con otros, los resultados pueden ser muy variables, lo que dependerá en cada caso de las características propias de cada subcuenca como: los usos del suelo, la pendiente de la corriente, el período hidrológico, las condiciones climatológicas; la altura, el caudal, presencia de interceptores marginales, etc. El aporte de este trabajo es el manejo de nuevos indicadores que enriquecen la información epidemiológica de la comunidad y profundiza el análisis sobre la calidad de los ríos, y que junto a los tradicionales orientan a la identificación del origen de la contaminación, importante para la toma oportuna de las medidas de prevención.

\section{CONCLUSIONES}

En este estudio, los microorganismos estreptococos fecales y enterococos han demostrado un desempeño satisfactorio como indicadores de contaminación fecal; son sensibles a cambios en la calidad del agua, manifestándose en cifras bajas en zonas de poca contaminación e incrementándose progresivamente a medida que la polución aumenta. Su magnitud es menor comparada con los habituales indicadores coliformes totales y fecales, lo que significa también valores más confiables ya que la mayoría de las especies no proliferan en medios acuáticos; es decir revelarían la contaminación original de la muestra. El período hidrológico: caudal alto, caudal medio y bajo, parece no tener influencia significativa en la magnitud de todos los indicadores; en general hay una ligera tendencia a presentar niveles más altos cuando también lo son los caudales.

Al establecer de manera aproximada el origen de la contaminación humana o animal, mediante la relación coliformes fecales/estreptococos fecales, se concluye que en los ríos Tomebamba y Tarqui, la mayor contaminación es de origen humano y debida a descargas de aguas residuales domésticas no interceptadas, situación que puede controlarse en parte. En el río Yanuncay también predomina la contaminación de origen humano, pero de naturaleza difusa y difícil de controlar; y en el río 
Machángara prevalece la contaminación por aguas residuales domésticas y en menor proporción la mixta, pero a diferencia de los otros ríos, la calidad depende menos del período hidrológico o caudal, lo que representa una ventaja en cuanto a los usos del recurso.

La construcción de los interceptores marginales, onerosa obra de infraestructura sanitaria todavía no consigue llevar la contaminación fecal de los ríos al objetivo de calidad planteado: $(\mathrm{NMP} / 100 \mathrm{ml}=1000)$; por lo que se sugiere una revisión rigurosa de las conexiones de los sistemas de alcantarillado hacia los interceptores marginales. No obstante, es importante también revisar el objetivo de calidad propuesto, ya que la meta puede ser muy ambiciosa y difícil de alcanzar, debido a la contaminación difusa no controlable que en algún momento presentan todos los ríos. No hay un indicador universal de calidad de agua; por lo tanto, se debe seleccionar el grupo bacteriano apropiado para la situación concreta objeto de estudio, ya que ningún grupo por sí solo posee la membresía en la predicción de presencia o ausencia de patógenos.

Este trabajo será entregado a los Organismos que tienen a su cargo la administración del recurso y la formulación de normativa: ETAPA EP, SENAGUA, Ministerio del Medio Ambiente, INEN, para que consideren la valía de los estreptococos y enterococos como indicadores complementarios al evaluar la calidad de ecosistemas como los ríos y aguas recreativas. Con estos resultados se pretende llamar la atención sobre la problemática ambiental de alta contaminación fecal en las zonas bajas de estas microcuencas, y constituyen un insumo que permite la implementación de medidas correctoras y/o protectoras de los cuerpos superficiales: protección de fuentes de agua, control de vertidos, revisión de conexiones domiciliarias, etc.

\section{RECOMENDACIONES}

- Para diferenciar el origen de la contaminación, además de los coliformes totales y fecales, se recomienda la determinación de los estreptococos fecales y enterococos; y para una interpretación más acertada, investigaciones posteriores deben enfocarse en la identificación de géneros y especies, mediante pruebas bioquímicas y/o serológicas específicas.

- Se debe tener presente en los controles sistemáticos de la calidad del agua potable, la probable presencia de virus (fagos) y parásitos como Cryptosporidium y Giardiasis, los cuales son muy resistentes a los procesos de desinfección con cloro (Campos-Pinilla, CárdenasGuzmán, \& Guerrero-Cañizares, 2008), y que no guardan ninguna relación con los indicadores estudiados.

- Debido a la frecuente contaminación y de muy diferentes orígenes que experimentan los cuerpos receptores, la evaluación de su calidad debe cubrir todo el espectro patogénico que entrañan estos cuerpos de agua.

- Finalmente es necesario una concepción ecosistémica de los ríos; el agua es el elemento vital ligado íntimamente a los procesos funcionales del ecosistema; observarlo en su conjunto como el objeto de explotación y conservación es vital, si se quiere garantizar la disponibilidad del recurso en la calidad y cantidad que la población requiere.

\section{REFERENCIAS}

Arcos, M. D. P., Ávila, S., Estupiñán, S., \& Gómez, A. (2005). Indicadores microbiológicos de contaminación de las fuentes de agua. Nova, 3(4), 69. https://doi.org/10.22490/24629448.338

Barahona, Y., Luna, J., \& Romero, I. (2017). Calidad del agua de los rios. Red Científica. http://lunazul.ucaldas.edu.co/index.php/englishversion/91-coleccion-articulos-espanol/275-calidadbacteriologica-del-agua-de-los-rios

Barrera, G., Chang, I. W., Figueroa, A., Guzmán, X., Hernández, F., \& Saavedra, F. (1998). Estudio preliminar de contaminación bacteriológica en la laguna Pueblo Viejo, Veracruz, México. Revista Internacional de Contaminación Ambiental, 14(2), 63-68.

Barrera, G., Wong, I., Sobrino, A., Guzmán, X., Hérnandez, F., \& Saavedra, F. (1999). Evaluacion microbiologica de la laguna de Tamiahua, Veracruz. Hidrobiológica, 9(2), 125-134.

Bonifaz, E. (2018). Evaluación de la Contaminación Fecal de origen humano y animal en la cuenca alta del río Guayllabamba mediante indicadores virales. Project, 1-113. Disponible en https://www.researchgate.net/project/Evaluacion-de-lacontaminacion-fecal-de-origen-humano-y-animal-enla-cuenca-alta-del-rio-Guayllabamba-medianteindicadores-virales.

Botero, L., Zambrano, J. L., Oliveros, C., \& León, D. (2002). Calidad microbiológica del agua de un sistema de lagunas de estabilización a ser empleada en irrigación microbial quality of wastewater in a system of stabilization lagoons to be employed in irrigation. Revista de La Facultad de Agronomía, 19(4), 312-323.

Calderon, K. (2014). Contaminación fecal por enterococos en agua de mar de las playas de Huanchaco y Huanchaquito de Agosto 2013Enero2014. Tesis para obtener el título profesional de Biólogo-Pesquero, 1-68. Facultad de Ciencias Biológicas, Universidad Nacional de Trujillo. Disponible en http://dspace.unitru.edu.pe/bitstream/ handle/UNITRU/4385/Calderon\%20More\%20 Katia\%20Liseth.pdf? sequence $=1$ \&isAllowed $=y$.

Calvo, G., \& Mora, J. (2012). Contaminación fecal en varios ríos de la Gran Área Metropolitana y la Península de Osa. Revista Tecnología en Marcha, 25(4), 33-39. https://doi.org/10.18845/tm.v25i4.617

Cambruzzi, N. (2016). Indicadores de en el estuario del Río Negro Tesis de Grado, 1-64. Licenciatura en Ciencias del Ambiente, Universidad Nacional de Río Negro. Disponible en

https://microbioblogueando.files.wordpress.com/2017/ 05/cambruzzi-tesis-rio-negro-2016.pdf

Campos-Pinilla, C., Cárdenas-Guzmán, M., \& GuerreroCañizares, A. (2008). Performance of faecal contamination indicators in different type of waters from the sabana of Bogotá (Colombia). Universitas Scientiarum, 13(2), 103-108. 
Campos, V. (1983). Los microorganismos como indicadores de contaminación. Boletín Micológico, 1 , 181-186.

Chagas, C., Morettón, J., Santanatoglia, O. J., Paz, M., Muzio, H., Siervi, M., \& Castiglioni, M. (2006). Indicadores de contaminación biológica asociados a la erosión hídrica en una cuenca de Pampa Ondulada Argentina. Ci. Suelo, 24(1), 1-7.

Chagas, C., Morettón, J., Santanatoglia, O., Paz, M., Castiglioni, M., \& De Siervi, M. (2007). Indicadores biologicos de contaminación fecal en relación a la carga animal en una cuenca de Pampa Ondulada. XXI Congreso Nacional del Agua, Tucúman, Argentina, 8pp. https://doi.org/10.13140/2.1.4324.0644.

Chiroles, S., González, M. I., Torres, T., Valdés, M., \& Domínguez, I. (2007). Bacterias indicadoras de contaminación fecal en aguas del río Almendares (Cuba). Higiene y Sanidad Ambiental, 7, 222-227.

Cohen, J., \& Shuval, H.I. (1973). Coliforms, fecal coliforms, and fecal streptococci as indicators of water pollution. Water, Air \& Soil Pollution, 2, 85-95. https://doi.org/10.1007/BF005723392.

Díaz, M., Rodriguez, C., \& Raisa, D. (2010). Aspectos fundamentales sobre el género enterococcus como patógeno de elevada importancia en la actualidad. Revista Cubana de Higiene y Epidemiologia, 48(2), 147-161.

Djuikom, E., Njine, T., Nola, M., Sikati, V., \& Jugnia, L. B. (2006). Microbiological water quality of the Mfoundi River watershed at Yaoundé, Cameroon, as inferred from indicator bacteria of fecal contamination. Environmental Monitoring and Assessment, 122(1-3), 171-183. https://doi.org/10.1007/s10661-005-9172-7

EcuRed. (2001). Enterococos Intestinales. Disponible en https://www.ecured.cu/Enterococos_intestinales

EPA. (2012). Recreational Water Quality Criteria. U.S. Environmental Protection Agency, 1-69. Disponible en https://https://www.epa.gov/sites/production/files/2015 -10/documents/ rwqc2012.pdf

Formica, S., Sacchi, G., \& Campodonico, V. (2015). Modelado de calidad de agua en ríos de montaña con impacto antrópico. Caso de estudio: Sierra Chica de Córdoba, Argentina. Revista Internacional Contaminación Ambiental, 31(4), 327-341.

Fout, G. S., Borchardt, M. A., Kieke, B. A., \& Karim, M. R. (2017). Human virus and microbial indicator occurrence in public-supply groundwater systems: meta-analysis of 12 international studies. Hydrogeology Journal, 25(4), 903-919. https://doi.org/10.1007/s10040-017-1581-5

Gamarra, O., Barrena, M., Baboza, E., Rascón, J., \& Corroto, F. (2018). Fuentes de contaminación estacionales en la cuenca del río Utcubamba, región Amazonas, Perú. Arnaldoa, 25(1), 179-194. https://doi.org/10.22497/arnaldoa.251.25111

Glynn Henry, J., \& Gary Heinke, W. (2009). Ingeniería Ambiental. In: P. E. R. Vázquez (Ed.), Libro, segunda edición (Vol. 6, Issue 6). Prentice Hall, Inc.

Kacar, A. (2011). Analysis of spatial and temporal variation in the levels of microbial fecal. Ecological Indicators, 11(5), 1360-1365. https://doi.org/10.1016/j.ecolind.2011.02.010
Larrea-Murrell, J. A., Rojas-Badía, M. M., RomeuÁlvarez, B., Rojas-Hernández, N. M., \& HeydrichPérez, M. R. M. (2013). Bacterias indicadoras de contaminación fecal en la evaluación de la calidad de las aguas: revisión de la literatura. Revista CENIC : Ciencias Biológicas, 44(3), 24-34.

Lombardo, A. de la C. (2018). Impacto del cambio climatico sobre la prevalencia de indicadores microbiologico, patogenos y parametros fisico quimicos de aguas superficiales del rio La Villa usadas para actividades agricola y humana. Tesis de maestría, Universidad de Panamá (Vol. 10, Issue 1, pp. 279288). https://doi.org/10.1542/peds.2006-2099

Macler, B. A., \& Merkle, J. C. (2000). Current knowledge on groundwater microbial pathogens and their control. Hydrogeology Journal, 8(1), 29-40. https://doi.org/10.1007/PL00010972

Marchand, E. O. (2002). Microoorganismos indicadores de la calidad del agua de consumo humano en lima metropolitana. Tesis para optar al título profesional de Biólogo con mención Microbiología y Parasitología, 71pp. Facultad de Ciencias Biológicas, Universidad Nacional Mayor de San Marcos. Disponible en https://sisbib.unmsm.edu.pe/BibVirtualData/Tesis/Basi c/ Marchand_P_E/tesis_completo.pdf

Méndez, R. (2004). Desarrollo y validacion de una prueba de fácil aplicación para determinación de enterococos en agua de consumo humano. Tesis, Biblioteca Central de la Universidad de San Carlos de Guatemala. Disponible en http://www.biblioteca.usac.edu.gt/tesis/06/06_2252.pdf

Namhira, P., Barrera, G., \& Márquez, A. (2002). Contaminación por bacterias fecales en el Lago Huayamilpas, México D.F. Hidrobiológica, 12(2), 129-136.

Rají, M., Ibrahim, Y., Tytler, B., \& Ehinmidu, J. (2015). Faecal Coliforms (FC) and Faecal Streptococci (FS) ratio as tool for assessment of water contamination: A case study of River Sokoto, Northwestern Nigeria. The Asia Journal of Applied Microbiology, 2(3), 27-34. https://doi.org/10.18488/journal.33/2015.2.3/33.3.27. 34

Ríos, S., Agudelo, R., \& Gutiérrez, L. (2017). Patógenos e indicadores microbiológicos de calidad del agua para consumo humano. Revista Facultad Nacional de Salud Pública, 35(2), 236-247. https://doi.org/10.17533/udea.rfnsp.v35n2a08

RIPDA CYTED. (2016). Capítulo 20 Indicadores de contaminacion fecal en aguas. RIPDA CYTED, 224-229. Disponible en http://tierra.rediris.es/hidrored/ ebooks/ripda/pdfs/Capitulo_20.pdf

Rivera, R., de Los Ríos, P., \& Contreras, Á. (2010). Relations fecal coliforms/ fecal Streptococci as indicators of the origin of fecal pollution in urban and rural water bodies of Temuco, Chile. Ciencia e Investigación Agraria, 37(2), 141-149. https://doi.org/10.4067/s0718-16202010000200014

Rodríguez, A., \& Ramón, D. (1990). Genetics of lactic acid bacteria with special reference to lactococci. Microbiología, 6(2), 51-64.

Rodríguez, D. (2011). Distribución de enterococos como indicadores de contaminación fecal en aguas de la Bahía De Tumaco, Pacífico Colombiano. Revista Cubana de Higiene y Epidemiologia, 50(2), 136-148. 
Rossen, A., Rodríguez, M. I., Ruibal Conti, A. L., Fortunato, M. S., Bustamante, A., Ruiz, M., Angelaccio, C., \& Korol, S. (2008). Indicadores bacterianos de contaminación fecal en el embalse San Roque (Córdoba, Argentina). Higiene y Sanidad Ambiental, 8, 325-330.

Salas, H. (2000). Historia y aplicación de normas microbiológicas de calidad de agua en el medio marino. OPS/CEPIS/PUB/00.53, 27 pp. Disponible en https://www.academia.edu/4467134/ HISTORIA_Y_APLICACI\%C3\%93N_DE_NORMAS _MICROBIOL\%C3\%93GICAS_DE_CALIDAD_DE_ AGUA_EN_EL_MEDIO_MARINO

Singh, K., Mishra, S., Lal Dwivedi, S., \& Kumar, R. (2019). Study of microbial pollution in River Beehar Water District Rewa Madhya Pradesh, India. Journal of Engineering Research and Application, 9(1), 24-29. https://doi.org/10.9790/9622

Sinton, L. W., Donnison, A. M., \& Hastie, C. M. (1993). Faecal streptococci as faecal pollution indicators: A review. Part II: Sanitary significance, survival, and use. New Zealand Journal of Marine and Freshwater Research, 27(1), 117-137. https://doi.org/10.1080/00288330.1993.9516550
Suarez, M. (2002). Tendencia actual del estreptococo como indicador. Revista Cubana de Higiene y Epidemiología, 40(1), 38-43.

Vanegas, L. (2012). Indicadores de Contaminación fecal en la subcuenca del Río Gil González. Universidad y Ciencia, 6(9), 31-37.

https://doi.org/10.5377/uyc.v6i9.1954

Vergaray, G., Méndez, C., Morante, H., Heredia, V., \& Béjar, V. (2007). Enterococcus y Escherichia coli como indicadores de contaminación fecal en playas costeras de Lima. Revista Del Instituto de Investigación de La Facultad de Ingeniería Geológica, Minera, Metalurgica y Geográfica, 10(20), 82-86.

WHO. (1997). The world health report 1997 conquering suffering, enriching humanity. Geneva, Switzerland: The World Health Organization. Disponible en https://www.who.int/whr/1997/en/ 